\title{
İlk Doğum Kararının Sosyoekonomik Belirleyicileri: Eş Zamanlı Hazard Modelleri
}

\author{
Egemen IPEK*
}

ÖZ

$\mathrm{Bu}$ çalışmada kadınların ilk doğum kararını etkileyen sosyoekonomik faktörlerin eş zamanlı hazard modelleri yardımıyla belirlenmesi amaçlanmıştır. Bu bağlamda TÜíK 2015 Hanehalkı Bütçe Anketi verileri kullanılarak yarı parametrik orantılı hazard modelleri çerçevesinde kişinin ve eşinin yaşı, eğitim seviyesi, engellilik durumu ile hanehalkı büyüklüğ̈̈ ve kadının gelirinin ilk doğum kararı üzerindeki etkileri tespit edilmiştir. Yapılan analizde veri setindeki eş zamanlı gözlemlere rastlanılması nedeniyle Efron, Breslow ve Kesin hazard yakınsamaları kullanılmıştır. Efron orantılı hazard model yakınsamasının daha tutarlı sonuçlar verdiği görülmüştür. Ayrıca ilk doğum kararının ertelenmesinde en önemli etkenlerin sırasıyla kadının engel durumu, yaşı ve eğitim durumu olduğu sonucuna ulaşılmıştır.

Anahtar Kelimeler: İlk Doğum, Çocuk Sahibi Olmak, Annelik, Eş-Zamanlı Orantısal Hazard Modeli,
Yaşam Analizi

JEL Sınıflandırması: J13, C41, R20

\section{Socioeconomic Determinants of First Birth Decisions: Tied Hazard Models}

\begin{abstract}
In this study, it is aimed to determine the socioeconomic factors that affect the first birth decision of women using the tied hazard models. In this context, the effect of woman's age, education level, disability status, household size and income on the first birth decision are determined applying semi-parametric Efron, Breslow and Exact approximations of tied hazard models on the Turkstat 2015 Household Budget Survey data because of the frequency of tied observations in the data set. In the analyzes, Efron approximation produced more consistent results. In addition, it is concluded that the most important factors in the first birth decision are disability status of the woman, age and her educational level.
\end{abstract}

Keywords: First Birth, Childbearing, Maternity, Tied Proportional Hazard Models, Survival Analysis

JEL Classification: J13, C41, R20

Geliş Tarihi / Received: 01.03.2019 Kabul Tarihi /Accepted: 08.04.2019

* Dr. Öğr. Üyesi, Gümüşhane Üniversitesi, İİBF, İktisat Bölümü, eipek@ gumushane.edu.tr, Ziyaretçi Dr. Öğr. Üyesi,
Brunel Üniversitesi Londra, Ekonomi ve Finans Bölümü, egemen.ipek@ brunel.ac.uk, ORCID: 0000-0002-1365-0526. 


\section{GİRIŞ}

Yakın zamana kadar ekonomistler doğurganlığın belirleyicilerinin büyük ölçüde ekonomik olmadığına ya da en azından doğurganlık analizinin ekonomik teori kapsamı dışında olduğuna inanmaktaydılar. Bu düşüncelerini doğum kararının geleneksel tüketici tercihleri teorisine dâhil edilmesindeki zorluklara ve gelirdeki artışın doğurganlığı arttıracağ1 yönündeki Neo-Malthusian görüşlere dayandırmaktaydılar. Ancak son yıllarda beşerî sermaye, zamanın kullanımı ve pazar dışı hanehalkı davranışlarının iktisat teorisine dâhil edilmesi ile doğurganlık analizinin yanı sıra evlilik, boşanma, doğum kontrolü, çocuk yetiştirme, okul eğitimi gibi demografik, sosyolojik değişkenler ile gelir, tüketim, tasarruf ve işgücü davranışı gibi daha geleneksel ekonomik değişkenlerin seçim teorik yaklaşım içerisinde analizi mümkün hale gelmiş̧ir. Bu yeni teorik yaklaşım ailenin ekonomik teorisi olarak adlandırılmaktadır (Wills, 1973). Becker (1963) modeli olarak da bilinen bu teorik yaklaşımda gelir, harcamalar, çocuğun kalitesi, zaman kısıdı, doğumun fırsat maliyeti gibi iktisadi kavramlar ile doğurganlığın ekonomik teorisi arasında bir ilişki kurulmuştur. $\mathrm{Bu}$ modelde ebeveynlerin fayda fonksiyonu kendi tüketimlerine ve çocuğun faydasına bağlıdır.

Çocuk sahibi olmak kadınların ve diğer aile üyelerinin yaşamlarındaki en önemli dönüşümlerden birisidir. Bu durum bireylerin yaşam tarzı üzerinde önemli değişiklikler yarattı̆̆ 1 gibi geriye dönülmeyecek şekilde etkiler meydana getirmektedir. Tüm gelişmiş ülkelerde olduğu gibi ülkemizde de kadınların ilk doğum yaş ortalamalarında artış gözlemlenmektedir. Nitekim Türkiye'de 2001 yılında kadınlarda ilk doğum yaş ortalaması 26,7 iken 2017 yılında 28,7'ye yükselmiş̧ir (Türkiye İstatistik Kurumu [TÜIKK], 2017). Kadınların ilk doğum yaşındaki artışlar doğurganlık üzerinde iki olası olumsuz etkiye neden olabilmektedir. Bunlardan birincisi, otuz yaşından sonra başarılı gebelik olasılı̆̆ının azalması nedeniyle gönülsüz çocuksuzluk durumunun oluşmasıdır (Leridon, 2004). 2006 yılında Türkiye'de çocuksuz ailelerin oranı $\% 13,1$ iken bu oran 2013 yılında \%16,2 seviyesine kadar yükselmiş olması bu durumu desteklemektedir (TÜIK, 2017). Her ne kadar çocuk sahibi olmamayı tercih eden bireylerin sayısında artış meydana gelse de genellikle birbirini izleyen ertelemeler nedeniyle çocuksuzluk durumu çoğunlukla istemsiz şekilde oluşmaktadır (Hobcraft ve Kiernan, 1995; Testa ve Toulemont, 2006; Tanturri ve Mencarini, 2008). İkinci olumsuz etki, rekabetçi yaşam koşullarındaki artış nedeniyle bireylerin çocuk sahibi olma isteklerini aşağı doğru revize etmeleridir (Morgan ve Taylor, 2006). Özellikle çocuk sahibi olmakla birlikte başlayan yoğun sorumluluklar ve çocuk bakımı, bireylerin çocuk sahibi olma kararı almalarını ertelemelerine sebep olmaktadır. Erteleme kararı biyolojik ve davranışsal nedenlerle gelecekteki aile büyüklügü üzerinde de azaltıcı etkiler yaratmaktadır (Rao ve Balakrishnan, 1988). Diğer yandan ilk doğum yaşının ertelenmesi, kadının iş gücüne katılmasına ve hane gelirini arttırmasına olanak sağlayarak hanenin ekonomik durumunun iyileşmesine yardımcı olmaktadır (Bratti ve Cavalli, 2013; Hauge ve Sayem, 2009).

Tavares, (2016), sosyal bilimler alanında yapılan çalışmalarda eğitimin ilk doğum yaşının gecikmesindeki en büyük "suçlu" olarak görüldüğünü belirtmektedir. Bunun ilk gerekçesi olarak bireylerin en azından eğitimlerini bitirene kadar çocuk sahibi olmay1 ertelemeleri gösterilebilir (Bhrolchain ve Beaujouan, 2012). Ancak bu gerekçe tek başına yeterli değildir. Çünkü bu durum bazı kadınların eğitimlerini tamamladıktan sonra çocuk sahibi olmak için aldıkları erteleme kararlarını neden hala devam ettirdiklerini ya da neden daha az eğitimli kadınların ilk doğumda daha yüksek yaşlara sahip olduğu gibi soruları cevaplayamamaktadır.

Eğitim ile ilk doğum yaşı arasındaki bir diğer ilişki annelik ile iş kariyeri arasındaki karşılıklı değiş tokuştan kaynaklanmaktadır. (Rindfuss vd., 1996; Gustafsson ve Kalwij, 2006). İktisadi perspektiften bakıldığında ilk doğumun ertelenmesi kararı beşerî sermaye açısından kilit rol oynamaktadır (Gustafsson, 2001). Çocuklarla ilgilenmek ve onları yetiştirmek önemli bir zaman harcanmasını gerektirdiği için, annelik dönemine geçişin iki önemli firsat maliyetine yol 
açtığ öne sürülmektedir. Bunlardan birincisi doğum nedeniyle işten çıkılan süre içinde ödenen ücretin mevcut firsat maliyetidir. İkincisi ise kariyer kesintisi nedeniyle beşerî sermaye birikiminin kesilmesi nedeniyle ortaya çıkan maliyetlerdir. Dolayısıyla iş kesintisi ne kadar erken olursa, maliyet de o kadar büyük olmaktadır (Cigno ve Ermisch, 1989). Söz konusu analık cezalarına dair yapılan ampirik çalışmalarda kadınların doğumla birlikte ciddi maliyetlere maruz kaldıklarına dair sonuçlar elde edilmiștir (Ellwood vd., 2004; Amuedo-Dorantes ve Kimmel, 2006; Correll vd., 2007; Miller, 2010; Van Bavel, 2010). Daha eğitimli kadınların daha yüksek kazanç profillerine sahip olacağı, dolayısıyla daha yüksek firsat maliyetleriyle karşı karşıya kalacakları düşünülmektedir. Kadınların daha yüksek maliyetlerle karşı karşıya kalmaları kadınların daha çok doğum erteleme kararı almalarına ve az sayıda çocuk doğurmalarına neden olabilmektedir (Liefbroer, 2005).

Virgina ve Runefeld (1997) engelli kadınların üreme haklarının birçok nedenle sınırlandığına işaret etmektedir. Bunlardan bazıları engelli kadınların aseksüel olduğu varsayımı, doğum kontrolü ve cinsellik bilgilerinin eksik olduğu, engelli kadınların üremeye ve anne olmaya karşı sosyal baskıya maruz kalmalarıdır. Rogers, (2006)'a göre engelli kadınlar bağımlı, başkasına bakamayan ve aseksüel olarak kabul edilirler. Ayrıca çocuk sahibi olması için sosyal ve duygusal baskı yaşayan birçok kadının aksine engelli kadınlar çocuk sahibi olmaması yönünde aynı baskılara maruz kalmaktadırlar. Engelli kadınların üreme hakları üzerine ve bu hakların korunup geliştirilmesi üzerine birçok platformda çalışmalar yapılmaktadır. Kuttai (2010) engelli kadınların çocuk sahibi olmaları halinde kendilerini daha dişi, daha seksüel ve tam bir kadın gibi hissetme olanağına kavuşacaklarını belirtmektedir. Engelliliğin yukarıda bahsedilen nedenlerden dolayı ilk doğum kararı üzerinde önemli negatif etkilere sahip olacağı düşünülmektedir. Bu nedenle çalışmada engellilik değişkeni analize dâhil edilmiştir.

Çocukların çoğu, ebeveynler tarafından dengeli bir ilişki içinde tasarlanır ve doğar. $\mathrm{Bu}$ durumda, çocuk sahibi olma kararı genellikle çiftler tarafından ortaklaşa alınır (Corijn vd, 1996). Doğurganlık ekonomisi üzerine yapılan ilk çalışmalarda doğum kararı genellikle kadına ait özellikler üzerinden araştırılırken, son yirmi yılda, doğurganlık karar verme modelleri çiftler arasındaki etkileşimi dikkate alarak ve çiftlere büyük önem vermektedir. Yapılan bu çalışmada çocuk sahibi olma kararının sadece kadın tarafından değil eşler tarafından ortaklaşa alındığı varsayılmıştır. $\mathrm{Bu}$ nedenle eşe ait sosyoekonomik değişkenler de ampirik modele eklenerek bu değişkenlerin etkileri araştırılmıştır. Nahar ve Zhangir, (2013) çalışmasında eşin eğitim durumu ile eşin sosyal statüsünün ilk doğum kararı üzerinde istatistiksel olarak anlamlı ve çocuk sahibi olma olasılığını arttırdığı tahmin edilmiştir.

Çalışmada ayrıca hane büyüklüğü değişkeni analize dâhil edilmiştir. Özellikle erken yaşlarda doğum yapan kadınların daha geniş aileye sahip olma olasılıklarının yüksek olduğu düşünülmektedir. Dahası kadınların erken yaşlarda doğum yaptığı topluluklarda nüfus artış hızının daha hızlı olduğuna dair ampirik bulgular elde edilmiştir (Senderowitz ve Paxman, 1985; Mazur, 1997; Singh, 1998). Bu açıdan değerlendirildiğinde hanehalkı sayısının ilk doğum kararı üzerinde etkili olduğu düşünülmektedir. Erken doğum kararı alan hanelerin daha fazla birey sayısına sahip olacağı beklenilmektedir.

Gelişmiş ve gelişmekte olan ülke örneklerine bakıldığında zamanla kadınların eğitim seviyesinin artması ve iş hayatında daha fazla yer edinmeleri nedeniyle evlilik ve anne olma kararlarını erteledikleri gözlemlenmektedir (Nahar ve Zhangir, 2013). Kadınların sosyoekonomik durumlarındaki ortalama artışın etkilerinin analiz edilebilmesi için ise çalışmada kadınların doğdukları döneme bağlı olarak oluşturulan gruplar ile kadınların doğdukları dönemin ilk doğum kararı üzerindeki etkileri tahmin edilmeye çalışılmıştır.

Türkiye özelinde ilk doğum kararının belirleyicileri üzerine yapılan çalışmalara bakıldığında ise söz konusu çalışmaların iktisadi bakış açısıyla değil sağlık bilimi açısından ele alındığı görülmektedir. Özkan ve Arslan (2007), çalışmasında Zeynep Kamil Kadın ve Çocuk 
Hastalıkları Eğitim ve Araştıra hastanesine başvuran 200 kadın üzerinden fizyolojik yakınmaların ilk doğum kararını nasıl etkilediği araştırılırken, Turan vd. (2005) çalışmasında ise Ankara/Aktepe 8 Nolu Ana-Çocuk Sağlığı ve Aile Planlaması Merkezi'ne gelen kadınlarda ilk evlilik ve ilk doğum yaşlarının, evlilikten sonra ilk doğuma kadar geçen süre ve öğrenim düzeyinin bunlar üzerindeki etkisi araştırılmıştır. Çalışmada yazarlar 1017 örneklem üzerinden yaptıkları analizde öğrenim düzeyinin artmasının ilk evlilik ve ilk doğum yaşlarını yükselttiği, ancak evlendikten ilk doğuma kadar geçen süreyi etkilemediği sonucuna ulaşmışlardır.

Türkiye özelinde yapılan az sayıdaki çalışmalar incelendiğinde çalışmaların tıp alanında ve sınırlı bir gözlem üzerinden yapıldığı görülmektedir. İktisadi teorisi açısından da önem verilen ve doğurganlığın ekonomik teorisi altında incelenen bu konunun sadece tıbbi bilimler açısından ele alınması ile ilk doğum kararının sosyoekonomik etkilerinin göz ardı edildiği görülmektedir. İlk doğum kararında tıbbi faktörler kadar sosyoekonomik değişkenlerin bu kararın üzerinde önemli etkileri olduğu bilinmektedir. Türkiye özelinde ise hem iktisadi perspektiften bu konuyu ele alan hem de ülke genelini kapsayan çalışmalara rastlanılmamaktadır. Tüm bu nedenlerle Türkiye genelinde ilk doğum kararına etki eden sosyoekonomik faktörlerin kadınların ilk doğum kararı üzerinde yarattığı etkileri inceleme zarureti nedeniyle bu çalışma hazırlanmıştır. Haliyle yapılan çalışma ile doğurganlık literatürüne önemli katkıların sağlanması beklenmektedir.

Yukarıda bahsedilen gerekçelerle bu çalışmada Türkiye'de evli kadınlarda ilk doğum kararı üzerinde kadının yaşı, eğitim seviyesi, engel durumu, geliri, kadının doğduğu dönem ile eşin yaşı, eğitim seviyesi, engel durumu ve gelir seviyesi gibi sosyoekonomik değişkenlerin etkisi analiz edilmiştir. İlk doğum kararı ile ilgi olduğu düşünülen söz konusu değişkenlerin etkisi 2015 yılı Hanehalkı Bütçe Anketi veri setinden yararlanılarak tahmin edilmiştir.

Çalışmada, söz konusu faktörlerin kadınların ilk doğum kararı üzerinde yarattı̆̆ 1 farklılıkların analizinde hazard modeli kullanılmıştır. Hazard modelleri araştırılan olguda gecen iki olay arasındaki süreyi analiz edebilmek için geliştirilmiştir. $\mathrm{Bu}$ yaklaşım bir olayın başlangıcından bitimine kadar geçen sürenin modellenmesinde tercih edilmektedir. Hazard modelleri karar vericilerin ilgilenilen süreç zarfında sürekli olarak kararlar aldığını varsayan dinamik bir yöntemdir (Şahin, 2001).

Çalışmanın sunumu şu şekilde planlanmıştır. Çalışmanın bundan sonraki bölümünde veri seti ve orantılı hazard modelleri hakkında bilgilere yer verilmektedir. İkinci bölümde modelin tahmin sonuçları tartışılmakta ve sonuç bölümüyle çalışma sona ermektedir.

\section{VERİ SETİ VE YÖNTEM}

Çalışmada ampirik modelin testi için 2015 Hanehalkı Bütçe Anketi (HBA) verilerinden yararlanılmış olup, ilk doğum kararını etkileyen faktörlerin belirlenmesinde aynı zamana gelen birden çok gözleme rastlanıldığı için eş zamanlı Cox orantılı hazard yöntemleri tercih edilmiştir. Çalışmanın bu kısmında ilk olarak veri seti tanıtılmış ardından eş zamanlı Cox orantılı hazard modelleri hakkında bilgiler verilmiştir.

\subsection{Veri Seti}

Çalışmada 2015 TÜİK HBA verilerinden yararlanılmıştır. Temsili grup olarak kadınların fiziksel olarak doğuma elverişli olduğu kabul edilen 15 yaş ile (Bloom ve Trussell, 1984; Groot ve Pott-Butter, 1992) Türkiye'de kadınların doğal menopoz yaşı olarak kabul edilen 46 yaş 
(Şenol vd., 1998; Yardımcı vd., 1996; Özdemir ve Çöl, 2004) arasındaki evli $5197^{1}$ kadın alınmış ve gruptaki kadınların ilk doğumlarına kadar geçen süreyi etkileyen sosyoekonomik faktörlerin etkisi araştırılmıştır. Çalışmada kullanılan sosyoekonomik değişkenlere ait özet istatistikler Tablo 1'de verilmiştir.

Tablo 1: Tanımlayıcı İstatistikler

\begin{tabular}{|l|c|c|c|c|}
\hline \multicolumn{1}{|c|}{ Değişken } & Ortalama & Std. Sapma & Minimum & Maksimum \\
\hline Eşin yaşı & 39,843 & 7,617 & 22 & 86 \\
\hline Eşin eğitim seviyesi & 2,121 & 1,254 & 0 & 5 \\
\hline Eşin engel durumu & 0,025 & 0,156 & 0 & 1 \\
\hline Eşin yıllık geliri & 28271 & 32713 & 0 & 1071099 \\
\hline Kadının yaşı & 35,518 & 6,642 & 16 & 46 \\
\hline Kadının eğitim seviyesi & 1,733 & 1,290 & 0 & 5 \\
\hline Kadının engel durumu & 0,013 & 0,116 & 0 & 1 \\
\hline Kadının yıllık geliri & 5432 & 12496 & 0 & 221440 \\
\hline Hane Büyüklüğ̈ & 4,270 & 1,596 & 2 & 20 \\
\hline
\end{tabular}

Yaş değiş̧keni, 2015 yılında bireylerin sahip olduğu yaşı gösterirken, eğitim değişkeni, okuma yazma bilmeyenler, ilkokul mezunu, ortaokul mezunu, lise mezunu, üniversite mezunu ve lisans üstü mezunları için sırasıyla 0-5 aralığında tam sayı değeri alan kategorik değişkendir. Bireylerin günlük yaşama engel oluşturan bir engele sahip olduklarında 1 diğer durumlarda 0 değerini alan kukla değişken aracılığıyla engellilik durumunun çocuk sahibi olmaya etkisi araştırılmıştır. Kullanılan veri setinde engelli kadın oranı $\% 1$ iken engelli eş oranı $\% 2$ seviyesindedir. Ortalama eğitim seviyelerine bakıldığında ise eşlerin yaklaşık ortaokul, kadınların ise ilkokul mezunu oldukları söylenebilir. Ayrıca kadınların doğum yıllarına bağlı olarak beşer yıllık aralıklarla 1969-74, 1975-79, 1980-84, 1985-89 ve 1990 sonrası doğanlar olmak üzere 5 grup oluşturulmuştur (Rao ve Balakrishnan, 1988; Mhele, 2015; Kingsley, 2018). Böylelikle doğum yılına bağlı olarak daha homojen gruplar üzerinden analiz yapılması avantajı elde edilmesi ile birlikte çocuk sahibi olma sürelerinde dönemsel bir değişiklik olup olmadığını da araştırma imkânına erişilmiştir. Son olarak analize dâhil edilen hanehalkı büyüklügüü değişkeni ile çocuk sahibi olma arasında iki temel ilişki olduğu düşünülmektedir. Bunlardan birincisi ölçek ekonomileri avantajları nedeniyle hanehalkı sayısı arttıkça kişilerin çocuk sahibi olma isteklerinin artmasıdır. İkincisi ise erken doğum yapanlarda hanehalkı büyüklügünün yüksek olma eğiliminde olduğudur (Haque ve Sayem, 2009; Ermisch ve Ogawa, 1994). Son olarak kadının cari gelir seviyesi açıklayıcı değişken olarak analize eklenmiştir. Kadınlarda sıfır gelirli gözlemlerin tüm gözlem sayısına oranı \%57,42 olduğundan gözlem kaybına neden olmamak için gelirin logaritması alınmadan nominal değer olarak modele eklenmiştir.

\subsection{Yöntem}

$\mathrm{Bu}$ kısımda yaşam süresi dağılımına ilişkin oranların zamana karşı sabit olması varsayımı ve bu varsayımın test edilmesini mümkün kılan çeşitli yaklaşımlar kısaca tanıtılmıştır. Hazard modellerinde zamanın yanında bireye ait değişkenlerin olayın gerçekleşmesine olan etkisi ve bu etkilerin büyüklükleri de eşanlı olarak tahmin edilmektedir (Rao ve Balakrishnan,

\footnotetext{
${ }^{1}$ Söz konusu 5197 gözlem örneklem ağırlığı olan Faktör değişkeniyle ağırlıklandırıldığında gözlem sayısı 10.071.486 olmaktadır.
} 
1998). Hazard modellerinde tanımlanan olay meydana gelene kadar geçen süre yaşam veya sağ kalım süresi olarak adlandırılmaktadır. Orantılı hazard modellerinde birbiriyle ilişkili iki önemli fonksiyon bulunmaktadır. Bunlardan birincisi hazard fonksiyonu diğeri ise yaşam fonksiyonudur. $\lambda(t)$ hazard fonksiyonu t zamanından önce bireyin doğum yapmaması koşuluna bağlı olarak bireyin t zamanında doğum yapma olasılığını tanımlarken, $\mathrm{S}(\mathrm{t})$ yaşam fonksiyonu ise doğum yapmamış bireyin doğum olana kadar geçen t zamanının olasılığını vermektedir. Cox orant1l1 hazard fonksiyonu Denklem (1)'de gösterilmiştir:

$$
\lambda(t ; z)=\lambda_{0}(t) e^{\left(\beta_{1} x_{1}+\beta_{2} x_{2}+\cdots+\beta_{k} x_{k}\right)}=\lambda_{0}(t) e^{\beta, z}
$$

Burada $\lambda_{0}(\mathrm{t})$ özel olarak tanımlanmamış temel hazard fonksiyonudur. Klasik regresyon analizindeki sabit gibi düşünülebilse de, sabitten farklı olarak her bir t zamanında farklı değerler almaktadır. $\beta$ açıklayıcı değişkenlere (covariates) ait tahmin edilen katsayıları temsil ederken, “z” k tane açıklayıcı değişkenin kümesi olarak tanımlanmaktadır. Denklem (1)'den hareketle temel grup için yaşam fonksiyonu aşağıdaki gibi ifade edilmektedir:

$$
S(t ; z)=\left[S_{0}(t)\right] e^{\left(\beta_{1} x_{1}+\beta_{2} x_{2}+\cdots+\beta_{k} x_{k}\right)}=\left[S_{0}(t)\right] e^{\beta, z}
$$

Denklem 2'den hareketle yarı parametrik Cox orantılı hazard eşitliğini iki farklı durum için doğrusal olarak ifade edildiğinde Denklem (3a) ve (3b) haline gelmektedir

$$
\begin{aligned}
& \eta_{i}=\beta_{1} x_{i 1}+\beta_{2} x_{i 2}+\cdots+\beta_{k} x_{i k} \\
& \eta_{i^{\prime}}=\beta_{1} x_{i^{\prime} 1}+\beta_{2} x_{i^{\prime} 2}+\cdots+\beta_{k} x_{i^{\prime} k}
\end{aligned}
$$

$\mathrm{Bu}$ iki durum için zamandan bağımsız hazard oranı ise Denklem 4'te gösterilmiştir.

$$
\frac{\lambda_{i}(t)}{\lambda_{i^{\prime}}(t)}=\frac{\lambda_{0}(t) e^{\eta_{i}}}{\lambda_{0}(t) e^{\eta_{i^{\prime}}}}=\frac{e^{\eta_{i}}}{e^{\eta_{i^{\prime}}}}
$$

Orantılı hazard modelinde temel varsayım orantılı hazard değerlerinin zamana karşı sabit olması durumudur. Bir başka ifadeyle, Denklem (4)'de görüldüğü üzere i ve i' birimlerine ait hazardlar orantılı olmak durumundadır. Yani hazardlardan elde edilen artıklar zamandan bağımsız olmak zorundadır. Orantılı hazard modellinin kullanılabilmesi için bu varsayımın sağlanması temel koşuldur. Söz konusu varsayımın sınanmasında Schoenfeld (1982) orantılı artıklar testi tercih edilmiştir. ${ }^{2} \mathrm{Bu}$ yöntemde, Grambsch ve Therneau (1994) tarafından genelleştirilen Schoenfeld orantılı artıkları kullanılarak zamanla ölçeklenmiş artıkların eğiminin sıfir olup olmadığı test edilir ve test sonucunda eğimin sıfır olmadığı durumda orantılı hazard varsayımının ihlal edildiği tespit edilir.

Denklem (1)'de her bir e ${ }^{\beta}$ katsayısı açıklayıcı değişkenlerin temel hazard fonksiyonuna etkisini temsil etmektedir. Eğer katsayı 1 ise değişkenin bir etkisinin olmadığı anlamına gelmekte, eğer katsayı 1'den farklı ise açıklayıcı değişkenin temel gruba göre hem sayısal ve hem de zamansal olarak etkili olduğu anlamına gelmektedir. Dolayısıyla katsayı 1'den büyük ise açıklayıcı değişkene sahip bireyin hem sayısal olarak daha fazla gözlemleneceği hem de zamansal olarak daha kısa sürede olayın gerçekleşeceği anlamına gelmektedir. İlk doğum kararı üzerinden örnek verilecek olursa, araştırılan değişken katsayısının 1'den büyük çıkması durumu, o özelliğe sahip bireylerden doğum yapmış olanların hem sayısının fazla olduğu hem de o özelliğe sahip bireylerin daha erken sürede çocuk sahibi oldukları (kararı aldıkları) şeklinde yorumlanmaktadır. Tersi durumda yani eğer katsayı 1'den küçük ise, kadının doğuma elverişli olduğu süre boyunca çocuk sahibi olma olasılı̆̆ı temel gruba göre azalmakta ve çocuk sahibi

\footnotetext{
${ }^{2}$ Orantılı hazard varsayımını test etmek için $\log (-\log )$ yasam eğrileri, Arjas grafikleri, beklenen ve gözlenen yaşam eğrileri gibi grafiksel yöntemler de mevcuttur. Ancak Schoenfeld test istatistiği, orantılı hazard varsayımının incelenmesi için kullanılan grafiksel yöntemlere göre daha nesnel bir kriter sağlamaktadır (Ata vd., 2007).
} 
olmak için geçen süre artmaktadır. Daha teknik bir ifade ile eğer katsayı 1'den küçük ise açıklayıcı değişken hazard fonksiyonu ile negatif, yaşam fonksiyonu ile pozitif ilişkilidir.

Temel hazardın belirlenmemiş olduğu durumda bile, Cox orantılı model en çok olabilirlik tahmin edicileri kullanılarak tahmin edilebilmektedir. Cox orantılı hazard modeli, hazard fonksiyonunun sürekli olduğunu varsaymakta ve bu nedenle eş zamanlı yaşam sürelerinin olmadığ kabul edilmektedir (Picciotto ve Rockhill, 1997; Xin, 2011). Ancak yaşam süreleri verileri derlenme aşamasında en yakın zaman dilimine (ay, gün, yıl gibi) göre oluşturulmakta ve bu nedenle eş zamana sıklıkla rastlanılmaktadır. Bu çalışmada yaşam süresinin yıl olarak belirlenmesinden dolayı veri bir zamanda birden çok doğum meydana geldiği gibi birden çok durdurulmuş gözlem de eş zamanlı olarak yer almaktadır. Bu nedenle bu gibi eş zamanlı gözlemlerin olduğu durumlarda Cox orantılı hazard modelleri için Efron (1977), Breslow (1974) veya Kesin (exact) olabilirlik fonksiyonları önerilmiştir. Efron, Breslow veya Kesin yaklaşımları kullanılarak yapılan hazard model tahminlerinden hangisinin daha iyi olduğuna ise $-2 \log (\mathrm{L})$, Akaike Bilgi Kriteri (AIC) ve Bayesyen Bilgi Kriterine (BIC) bakılarak karar verilmektedir. Buradan, en düşük bilgi kriteri değerine sahip olan modelin daha iyi olduğu sonucuna ulaşılmaktadır (Klein ve Moeschberger, 1997; Borucka, 2014).

\section{BULGULAR}

Uygulamada 2015 HBA verilerinden yararlanarak 15-46 yaş aralığındaki evli kadınların ilk doğum yapma kararını (yıl bazında) etkilediği düşünülen eşinin ve kendisinin yaşları, eğitim seviyeleri, engellilik durumları, hanehalkı büyüklüğü, kadınların doğduğu dönem grup değişkeni ile gelir seviyesi değişkenleri eş zamanlı Cox orantılı hazard modelleri çerçevesinde araştırılmıştır. Çalışmada ilk olarak orantılı hazard modellerinin temel varsayımı olan orantılı hazard varsayımı Schoenfeld artık testi ile sınanmıştır. Bu varsayım gereği artıklar ile zaman arasında bir bağlantı olmaması gerekmektedir. Schoenfeld artık testi sonuçları Tablo 2'de gösterilmiştir. Her bir değişken ve modelin tamamı için Schoenfeld artıklarının anlamlılığının p $>0.05$ olması nedeniyle orantılı hazard varsayımının sağlandığı görülmektedir.

Tablo 2: Schoenfeld Artıkları Orantılı Hazard Testi

\begin{tabular}{|l|c|c|c|c|}
\hline \multicolumn{1}{|c|}{ Değişken } & rho & chi2 & df & Prob>chi2 \\
\hline Eşin yaşı & 0,274 & 0,120 & 1,000 & 0,728 \\
\hline Eşin eğitim seviyesi & 0,026 & 0,000 & 1,000 & 0,966 \\
\hline Eşin engel durumu & 0,009 & 0,000 & 1,000 & 0,989 \\
\hline Eşin yıllık geliri & 0,106 & 0,030 & 1,000 & 0,866 \\
\hline Kadının yaşı & 0,120 & 0,030 & 1,000 & 0,853 \\
\hline Kadının eğitim seviyesi & 0,026 & 0,000 & 1,000 & 0,968 \\
\hline Kadının engel durumu & 0,015 & 0,000 & 1,000 & 0,981 \\
\hline Kadının yıllık geliri & 0,157 & 0,030 & 1,000 & 0,861 \\
\hline Hane büyüklü̆̆̈ & 0,025 & 0,000 & 1,000 & 0,968 \\
\hline Global test & & 0,270 & 9,000 & 1,000 \\
\hline
\end{tabular}

Çalışmada eş zamanlı yaşam sürelerine rastlanılmasından dolayı Efron, Breslow ve Kesin Cox orantılı hazard modelleri kullanılmış ve sosyoekonomik faktörlerin ilk doğum kararı üzerindeki etkilere ait analiz sonuçları Tablo 3'de verilmiştir. İlk olarak Tablo 3'de yer alan bütün modellerin değişen varyans problemine karşı robust standart hataların üretildiği 
modellerde Wald $\mathrm{Chi}^{2}$ testi ve değișen varyansın olmadığı kesin hazard modelinde ise LR Chi ${ }^{2}$ değerlerine bakıldığında modellerin tümünde kullanılan açıklayıcı değişkenlerin $p<0,001$ anlamlılık seviyesinde anlamlı olduğu gözlemlenmektedir. Model karşılaştırmasında kullanılan bilgi kriterleri olan AIC ve BIC büyüklükleri değerlendirildiğinde ise en düşük değerin Efron hazard modeline ait olduğu görülmektedir. Çalışmada eş anlı gözlemlere sıklıkla rastlanılması nedeniyle model uyum iyiliği açısından en iyi modelin Efron hazard modeli olması beklentilerle örtüşmektedir. Çünkü eş anlı gözlemlerin yoğun olduğu veri setlerinde Efron modelinin daha tutarlı sonuçlar verdiği bilinmektedir (Picciotto ve Rockhill, 1997). Kesin marjinal hazard modelinin en yüksek bilgi kriteri değerlerine sahip olmasının yanında istatistiksel anlamlılığa sahip katsayıların diğer modellere göre az, tahmin edilen katsayı büyüklüklerinin ise yüksek olduğu görülmektedir. Breslow ile Efron hazard model sonuçları karşılaştırıldığında, katsayılar arasında çok önemli farklılıklar olmamakla birlikte Breslow modelinde tahmin edilen katsayıların Efron modelinden daha yüksek olduğu söylenebilir. Ayrıca Efron modelinden farklı olarak eşin günlük yaşama engel durumunun ilk doğum kararı üzerinde istatiksel olarak anlamlı bir etkisi de bulunmamaktadır. Çalışmada Efron ve Breslow modellerinde değişen varyans problemine karşın Robust standart hatalar üretilmiştir.

Efron orantılı hazard modeli tahminlerinin model uyum iyiliği en yüksek olan model olmasından hareketle çalışmada değişkenlere ait katsayı tahmin yorumları sadece bu model üzerinden yapılmıştır. Analizde tahmin edilen $e^{\widehat{\beta}_{i}}$ katsayısı hazard oranı olup katsayının 1'den büyük olması, o özelliğe sahip bireylerden doğum yapmış olanların hem sayısının fazla olduğunu hem de o özelliğe sahip bireylerin daha erken sürede çocuk sahibi olduklarını ima etmektedir. Aynı zamanda hazard oranına ait büyüklük değeri diğer değişkenler sabitken araştırılan değişkenin (veya referans kategoriye göre) yüzde cinsinden ne oranda etkilediğini gösterir ve $\left(e^{\widehat{\beta}_{i}}-1\right)$ işlemi yapılarak bu yüzdesel etki elde edilir. Analizde tahmin edilen bir diğer katsayı ise $\beta$ katsayısıdır. Bu katsayının pozitif değer alması bu düzeyin referans kategorisine göre daha fazla gözlemleneceğini, negatif değer alması ise bu düzeyin referans kategorisine göre daha az gözlemleneceğini göstermektedir. Bu açıklamalardan hareketle istatiksel olarak anlamlı ve en yüksek hazard oranı değerini alan hanehalkı büyüklüğü değişkeni, erken yaşta doğum yapanların daha kalabalık aileye sahip olmalarını (ilerleyen yaşta tekrar doğum yapmalarının) \%31 oranında daha fazla etkilediğini göstermektedir. Eşin yaşı arttıkça kadının erken yaşta doğum yapmasının olasılığını yaklaşık \%4 oranında arttırdığı gözlemlenmiştir.

Kadının ilk doğum kararını etkileyen etkenlere bakıldığında en önemli faktörün kadının günlük yaşamına engel bir durumunun olup olmaması olduğu görülmektedir. Kadına ait engel kukla değişkeni için tahmin edilen hazard oranı 0,695 olarak tahmin edilmiştir. Bu nedenle engelli kadın bireylerin engelli olmayan kadın bireylere nazaran üçte birinin çocuk sahibi olmayı planlamadıkları veya bu kararı engelli olmayan kadınlara istinaden daha geç aldıkları tahmin edilmiştir. Elde edilen bu sonuç kadının fiziksel ve ruhsal sağlığının çocuk sahibi olma üzerindeki negatif etkisi üzerine yapılan Mirowsky, (2005); Haque ve Sayem, 2009 ve Travers, (2016) çalışmaları ile örtüşmektedir.

Eşin günlük yaşama dair bir engelinin olması durumunda ise kadınların \%15,4'nün çocuk sahibi olma kararını ertelediği tahmin edilmiştir. Kadının yaşı ilerledikçe çocuk sahibi olma isteğinin \%12,3 oranında azaldığı soncuna ulaşılmıştır. Elde edilen bu sonuç beklenildiği hem davranışsal hem sağlık açısından bakıldığında literatür ile uyum içerisindedir. Kadınların doğum yıllarına göre oluşturulan grupların etkisine bakıldığında ise her beş yıllık dönemde çocuk sahibi olma isteğinin veya çocuk sahibi olma süresinin yaklaşık olarak \%12 seviyesinde ötelendiği tahmin edilmiştir. Özellikle gelişmekte olan ülkelerde kadınlarda ortalama eğitim seviyesinin artması, rekabetçi yaşam koşullarındaki artış gibi nedenlerle nesil etkisinin 
kadınlarda ilk doğum süresi üzerinde arttırıcı etkileye neden olduğu görülmektedir (Rao ve Balakrishnan, 1988; Mhele, 2015; Kingsley, 2018).

Tablo 3: Eş Zamanlı Hazard Model Tahmin Sonuçları

\begin{tabular}{|c|c|c|c|c|c|c|c|c|c|}
\hline \multirow{2}{*}{$\begin{array}{c}\text { Model: } \\
\text { Değişken }\end{array}$} & \multicolumn{3}{|c|}{ Efron Hazard Modeli } & \multicolumn{3}{|c|}{ Breslow Hazard Modeli } & \multicolumn{3}{|c|}{ Kesin Hazard Modeli } \\
\hline & $\begin{array}{c}\boldsymbol{e}^{\widehat{\beta}} \\
(\mathbf{R S H})\end{array}$ & $\begin{array}{c}\boldsymbol{\beta} \\
(\mathbf{R S H})\end{array}$ & p-değeri & $(\mathbf{R S H})^{e^{\widehat{\beta}}}$ & $\begin{array}{c}\boldsymbol{\beta} \\
(\mathbf{R S H})\end{array}$ & p-değeri & $(\mathbf{S H})^{e^{\widehat{\beta}}}$ & $\underset{(\mathbf{S H})}{\boldsymbol{\beta}}$ & $\begin{array}{c}\text { p- } \\
\text { değeri }\end{array}$ \\
\hline Eşin yaşı & $\begin{array}{r}1,043 * \\
(0,005)\end{array}$ & $\begin{array}{r}0,042 \\
(0,005)\end{array}$ & 0,000 & $\begin{array}{l}1,044 * \\
(0,005)\end{array}$ & $\begin{array}{r}0,040 \\
(0,004)\end{array}$ & 0,000 & $\begin{array}{c}1,010 * * * \\
(0,006)\end{array}$ & $\begin{array}{r}0,010 \\
(0,006)\end{array}$ & 0,077 \\
\hline $\begin{array}{l}\text { Eşin eğitim } \\
\text { durumu }\end{array}$ & $\begin{array}{r}1,016 \\
(0,017)\end{array}$ & $\begin{array}{r}0,016 \\
(0,017)\end{array}$ & 0,312 & $\begin{array}{r}1,013 \\
(0,016)\end{array}$ & $\begin{array}{r}0,013 \\
(0,015)\end{array}$ & 0,401 & $\begin{array}{r}1,042 \\
(0,035)\end{array}$ & $\begin{array}{r}0,041 \\
(0,034)\end{array}$ & 0,228 \\
\hline $\begin{array}{l}\text { Eşin engel } \\
\text { durumu }\end{array}$ & $\begin{array}{r}0,846^{* * * *} \\
(0,098)\end{array}$ & $\begin{array}{r}-0,168 \\
(0,116)\end{array}$ & 0,084 & $\begin{array}{r}0,854 \\
(0,092)\end{array}$ & $\begin{array}{r}-0,158 \\
(0,107)\end{array}$ & 0,105 & $\begin{array}{r}0,886 \\
(0,180)\end{array}$ & $\begin{array}{r}-0,121 \\
(0,203)\end{array}$ & 0,553 \\
\hline Kadının yaşı & $\begin{array}{r}0,876^{*} \\
(0,010)\end{array}$ & $\begin{array}{r}-0,133 \\
(0,012)\end{array}$ & 0,000 & $\begin{array}{l}0,882 * \\
(0,010)\end{array}$ & $\begin{array}{r}-0,125 \\
(0,011)\end{array}$ & 0,000 & $\begin{array}{l}0,920 * \\
(0,019)\end{array}$ & $\begin{array}{r}-0,083 \\
(0,020)\end{array}$ & 0,000 \\
\hline $\begin{array}{l}\text { Kadının eğitim } \\
\text { durumu }\end{array}$ & $\begin{array}{l}0,903 * \\
(0,015)\end{array}$ & $\begin{array}{r}-0,102 \\
(0,016)\end{array}$ & 0,000 & $\begin{array}{l}0,908 * \\
(0,014)\end{array}$ & $\begin{array}{r}-0,096 \\
(0,015)\end{array}$ & 0,000 & $\begin{array}{r}1,033 \\
(0,036)\end{array}$ & $\begin{array}{r}0,032 \\
(0,035)\end{array}$ & 0,356 \\
\hline $\begin{array}{l}\text { Kadının yıllık } \\
\text { geliri }\end{array}$ & $\begin{array}{l}1,000^{*} \\
(0,000)\end{array}$ & $\begin{array}{r}0,000 \\
(0,000)\end{array}$ & 0,000 & $\begin{array}{l}1,000^{*} \\
(0,000)\end{array}$ & $\begin{array}{r}0,000 \\
(0,000)\end{array}$ & 0,000 & $\begin{array}{l}1,000^{*} \\
(0,000)\end{array}$ & $\begin{array}{r}0,000 \\
(0,000)\end{array}$ & 0,245 \\
\hline $\begin{array}{l}\text { Kadının engel } \\
\text { durumu }\end{array}$ & $\begin{array}{l}0,695^{*} \\
(0,130)\end{array}$ & $\begin{array}{r}-0,364 \\
(0,188)\end{array}$ & 0,005 & $\begin{array}{l}0,715^{*} \\
(0,124)\end{array}$ & $\begin{array}{r}-0,336 \\
(0,173)\end{array}$ & 0,010 & $\begin{array}{r}0,869 \\
(0,196)\end{array}$ & $\begin{array}{r}-0,141 \\
(0,225)\end{array}$ & 0,532 \\
\hline Hane büyüklüğü & $\begin{array}{l}1,351 * \\
(0,022)\end{array}$ & $\begin{array}{r}0,301 \\
(0,016)\end{array}$ & 0,000 & $\begin{array}{l}1,356^{*} \\
(0,020)\end{array}$ & $\begin{array}{r}0,282 \\
(0,015)\end{array}$ & 0,000 & $\begin{array}{l}1,468 * \\
(0,020)\end{array}$ & $\begin{array}{r}0,384 \\
(0,014)\end{array}$ & 0,000 \\
\hline Grup & $\begin{array}{r}0,881 * * \\
(0,048)\end{array}$ & $\begin{array}{r}-0,126 \\
(0,055)\end{array}$ & 0,011 & $\begin{array}{r}0,887 * * \\
(0,045)\end{array}$ & $\begin{array}{r}-0,120 \\
(0,050)\end{array}$ & 0,016 & $\begin{array}{r}1,003 \\
(0,103)\end{array}$ & $\begin{array}{r}0,003 \\
(0,103)\end{array}$ & 0,980 \\
\hline Wald chi2 & & & 947,38 & & & 1022,53 & & & $\mathrm{n} / \mathrm{a}$ \\
\hline LR chi2 & & & $\mathrm{n} / \mathrm{a}$ & & & $\mathrm{n} / \mathrm{a}$ & & & 628,10 \\
\hline Prob > chi2 & & & 0,000 & & & 0,000 & & & 0,0000 \\
\hline AIC & & & 70789,81 & & & 71675,31 & & & 7495,4 \\
\hline BIC & & & 70848,81 & & & 71734,31 & & & 7554,4 \\
\hline$-2 \log (\mathrm{L})$ & & & 70771,80 & & & 71657,30 & & & 7477,4 \\
\hline
\end{tabular}

Son olarak kadının cari gelirinin çocuk sahibi olma kararında veya doğum erteleme süresi üzerinde bir etkisinin olmadığ gözlemlenmiştir. Bu durum giriş bölümünde detaylı olarak ele alındığı üzere kadının gelir ve beşerî sermaye birikimi kaynaklı yükselen alternatif maliyetler nedeniyle çocuk sahibi olma isteğinin ertelendiğine dair görüşler ile çelişkilidir. Bu sonucun elde edilmesindeki en önemli sebebinin örneklemde yer alan kadınların \%57,42'sinin gelirinin sıfır olmasından kaynaklandığı düşünülmektedir. Kadının gelir seviyesi yerine proxy değişken olarak eğitim seviyesinin kullanılması halinde elde edilen sonuçlar ampirik bulgular ile uyumludur. Kadınlarda eğitim seviyesindeki artışın çocuk sahibi olma isteğini \%9,7 oranında ötelenmesine neden olduğu tahmin edilmiştir.

\section{SONUC}

$\mathrm{Bu}$ çalışmada Türkiye'de evli kadınların ilk doğum kararı aldıkları süreyi etkileyen sosyoekonomik faktörlerin orantılı hazard modelleri yardımıyla belirlenmesi amaçlanmıştır. Hazard modelleri araştırılan konuda iki olay arasında geçen süreyi analiz edebilmek için geliştirilmiştir. Dolayısıyla bu yaklaşım bir olayın başlangıcından bitimine kadar geçen sürenin modellenmesinde sıklıkla tercih edilmektedir. Çalışmada 2015 Hanehalkı Bütçe Anketi verileri kullanılarak 15-46 yaş aralığındaki evli kadınlarda ilk doğuma kadar geçen süreyi (yıl bazında) etkileyen sosyoekonomik değişkenler (eşinin ve kendisinin yaşı, eğitim seviyesi, engellilik durumu, hanehalkı büyüklüğü, kadınların doğduğu dönem değişkeni) ile kadının gelir seviyesi olarak belirlenmiştir. Çalışmada ilk doğum süresi yıl bazında belirlendiği için aynı zaman 
dilimine denk gelen çok sayıda gözlemin var olmasından dolayı eş zamanlı Cox orantılı hazard yöntemlerinden olan yarı parametrik Efron, Breslow ve Kesin hazard modelleri tercih edilmiştir.

Analizde ilk olarak eş zamanlı gözlemlerin sıklığı ve yoğunluğu nedeniyle Efron orantılı hazard modelinin diğer eş zamanlı hazard yöntemlerine göre model uyum iyiliğinin yüksek olduğu görülmüştür. Sonrasında kadınların doğum kararını etkileyen değişkenlere bakıldığında en önemli negatif etkinin sırasıyla kadının engel durumu ve eşin engel durumu olduğu tahmin edilmiştir. Ardındın kadının eğitim durumu ve yaşının ilk doğum süresini uzattığı gözlemlenmiş, eşin yaşı yüksek olan kadınların daha erken yaşta doğum yaptıkları ve erken yaşta doğum yapanların daha yüksek hanehalkı büyüklüğüne sahip olma eğiliminde oldukları sonucuna ulaşılmıştır.

Yapılan bu çalışmada veri setinden kaynaklanan bazı kısıtlamalar mevcuttur. Özellikle engelli gözlem sayısının az oluşu, evlilik süresi, anne veya babanın kardeș sayısı, sahip olunan kültürel farklılıklar, çalışılan iş kolu ve bu iş kolunda çalışılan süre gibi değişkenleri içerecek şekilde oluşturulan veri setleri sayesinde bu konuda yapılacak çalışmaların nitelik ve niceliğinin artması imkânına erişilecektir. Öte yandan ilk doğum karar süresini etkileyen faktörlerin parametrik hazard modelleri çerçevesinde analiz edilmesi ve bu çalışmadan elde edilen yarı parametrik model sonuçları ile karşılaştırılmasının ampirik açıdan faydalı olacağı düşünülmektedir.

\section{KAYNAKÇA}

Amuedo-Dorantes, C. ve Kimmel, J. (2006), The Family Earnings and Postponement of Maternity in The United States, içinde Gustfasson, S. ve Kalwij, A. (Eds.), Education and Postponement of Maternity, Hollanda, Springer, 175206.

Ata N., Karasoy, D.S. ve Sözer, M. T. (2007), Orantılı Tehlike Varsayımının İncelenmesinde Kullanılan Yöntemler ve Bir Uygulama, Eskişehir Osmangazi Üniversitesi Mühendislik ve Mimarlık Fakültesi Dergisi, 20(1), 57-80.

Bhrolchain, M. N., ve Beaujouan, E. (2012), Fertility Postponement is Largely Due to Rising Educational Enrolment, Journal of Demography, 66(3), 311-327.

Borucka, J. (2014), Methods for Handling Tied Events in The Cox Proportional Hazard Model, Studia Oeconomica Posnaniensia, 2(2), 91-106.

Bloom, D. E. ve Trussell, J. (1984), What are the Determinants of Delayed Childbearing and Permanent Childlessness in the United States?, Demography, 21(4), 591-611.

Bratti, M. ve Cavalli, L. (2013), Delayed First Birth and New Mothers' Labor Market Outcomes: Evidence From Biological Fertiliy Shocks, IZA Discussion Paper, No7135.

Breslow, N.E. (1974), Covariance Analysis of Censored Survival Data, Biometrics, 30, 89-99.

Cigno, A. ve Ermisch, J. (1989), A Microeconomic Analysis of the Timing of Births, European Economic Review, 33(4), 737-760.

Corijn, M., Liefbroer, A. C., \& de Jong Gierveld, J. (1996). It Takes Two to Tango, Doesn't It? The Influence of Couple Characteristics on the Timing of the Birth of the First Child. Journal of Marriage and the Family, 117-126.

Correll, S. J., Benard, S. ve Paik, I. (2007), Getting a Job: is There a Motherhood Penalty?, American Journal of Sociology, 112(5), 1297-1338.

Cox, D. R. (1972), Regression Models and Life-Tables, Journal of The Royal Statistical Society: Series B (Methodological), 34(2), 187-202.

Efron, B. (1977), The Efficiency of Cox's Likelihood Function for Censored Data, Journal of The American Statistical Association, 76, 312-319.

Ellwood, D., Wilde, T. ve Batchelder, L. (2004), The Mommy Track Divides: The Impact of Childbearing on Wages of Women of Differing Skill Levels, Basılmamış Yayın.

Ermisch, J. ve Ogawa, N. (1994), Age at Motherhood in Japan, Journal of Population Economics, 7(4), 393-420. 
Grambsch, P. M. ve Therneau, T. M. (1994), Proportional Hazards Tests and Diagnostics Based on Weighted Residual, Biometrika 81, 515-526.

Groot, W., \& Pott-Buter, H. A. (1992), The timing of Maternity in the Netherlands, Journal of Population Economics, $5(2), 155-172$.

Gustafsson, S. (2001), Optimal Age at Motherhood. Theoretical and Empirical Considerations on Postponement of Maternity in Europe, Journal of Population Economics, 14, 225-247.

Gustafsson, S. ve Kalwij, A. (2006), Education and Postponement of Maternity: Economic Analyses for Industrialized Countries, Hollanda, Springer,1-25.

Haque A. M. ve Sayem, A. M. (2009), Socioeconomic Determinants of Age at First Birth in Rural Areas of Bangladesh, Asia Pacific Journal of Public Health, 21(1), 104-111.

Hobcraft, J. ve Kiernan, K. (1995), Becoming a Parent in Europe, içinde International Union for The Scientific Study of Population, Evolution or Revolution in European Population,1-58.

Kingsley, M. (2018) The influence of Income and Work Hours on First Birth for Australian Women, Journal of Population Research, 35(2), 107-129.

Klein, J.P. ve Moeschberger, M.L. (1997), Survival Analysis Techniques for Censored and Truncated Data, Springer, New York, 21-57.

Kuttai, H. (2010), Maternity Rolls: Pregnancy, Childbirth and Disability, Fernwood Publishing, 70.

Leridon, H. (2004), Can Assisted Reproduction Technology Compensate for The Natural Decline in Fertility With Age? A Model Assessment, Human Reproduction, 19, 1548-1553.

Liefbroer, A. C. (2005), The Impact of Perceived Costs and Rewards of Childbearing on Entry into Parenthood: Evidence from a Panel Study, European J. of Population, 21, 367-391.

Mazur, L. A. (1997). High Stakes: The United States, Global Population and Our Common Future, New York: The Rockefeller Foundation.

Mirowsky, J. (2005), Age at First Birth, Health, and Mortality, Journal of Health and Social Behavior, 46.1: 32-50.

Miller, A. (2010), The Effects of Motherhood Timing on Career Path, Journal of Population Economics, 24(3), 10711100.

Mhele, K. (2015). Determinants of Time to First Birth Among Women in Ages 15-24 in Swaziland, African Population Studies, 29(2).

Morgan, S. P. ve Taylor, M. G. (2006), Low Fertility at The Turn of The Twenty-First Century, Annual Review of Sociology, 32, 375-399.

Nahar, M. Z., \& Zahangir, M. S. (2013). Patterns and Determinants of Age at First Birth in Bangladesh. Turk J Popul Stud, 35, 63-77.

Özdemir, O., ve Çöl, M. (2004). The Age at Menopause and Associated Factors at the Health Center Area in Ankara, Turkey. Maturitas, 49(3), 211-219.

Özkan, A. ve Arslan, H. (2007). Gebeliğe Karar Verme, Fizyolojik Yakınmaları Algılama ve Eğitim Gereksinimleri. Zeynep Kamil Tıp Bülteni, 38(4), 155-161.

Picciotto, I.H. ve Rockhill, B. (1997), Validity and Efficiency of Approximation Methods for Tied Survival Times in Cox Regression, Biometrics, 53, 1151-1156.

Rao, K., ve Balakrishnan, T. (1988), Age at First Birth in Canada: A Hazards Model Analysis, Genus, 44(1/2), 53-72.

Rindfuss, R. R., Morgan, S. P. ve Offutt, K. (1996), Education and The Changing Age Pattern of American Fertility: 1963-1989, Demography, 33, 277-290.

Rogers, J. 2006. The Disabled Woman's Guide to Pregnancy and Birth. New York: Demos Medical Publishing, 1-3.

Schoenfeld, D. (1982), Partial Residuals for The Proportional Hazards Regression Model, Biometrika, 69, 239-41.

Senderowitz, J. ve Paxman, J. (1985). Adolescent Fertility: Worldwide Concerns, Population Bulletin, 40(2):3-51

Singh, S. (1998). Adolescent Childbearing in Developing Countries: A Global Review, Studies in Family Planning, 29(2):117-136.

Şahin, H. (2014), 1986-1991 Dönemi Türkiye Grevlerinin Bir Analizi: Hazard Modeli Yaklaşımı, Ankara Üniversitesi SBF Dergisi, 56 (03), 141-156. 
Şenol, V., Özdemir, A., Çetinkaya, F. ve Özturk, Y. (1998) Evaluation in Terms of Affecting Factors of Age at Menopause, içinde VI. National Public Health Congress Book; 362-364.

Tanturri, M. L. ve Mencarini, L. (2008), Childless or Childfree? Paths to Voluntary Childlessness in Italy, Population and Development Review, 34(1), 51-77.

Tavares, L.P. (2016), Who Delays Childbearing? The Associations Betweentime to First Birth, Personality Traits and Education, European Journal of Population (2016) 32, 575-597.

Testa, M. R. ve Toulemont, L. (2006), Family Formation in France: Individual Preferences and Subsequent Outcomes, içinde Vienna Yearbook of Population Research, 41-75.

Turan T., Bayoğlu Y., Yılmaz, N. ve Temürtürkan, G. (2005), Ankara/Aktepe 8 Nolu Ana-Çocuk Sağlığı ve Aile Planlaması Merkezi'ne Gelen Kadınlarda İlk Evlilik Yaşı, İlk Doğum Yaş1 ve Evlendikten İlk Doğuma Kadar Geçen Süre, Klinik Bilimler \& Doktor, 11(6); 734-738

TÜİK (2015), Hanehalkı Bütçe Anketi Mikro Veri Seti

TÜİK (2017), İstatistiklerle Aile Haber Bültenleri ve Veri Setleri

Van Bavel, J. (2010), Choice of Study Discipline and The Postponement of Motherhood in Europe: The Impact of Expected Earnings, Gender Composition and Family Attitudes, Demography, 47, 439-458.

Virginia, K. ve Phyllis, R. (1997), Disabled Women and Reproductive Rights, Disability \& Society, 12:2, 203-222,

Willis, R.J., (1973), “A New Approach to the Economic Theory of Fertility Behavior “, Journal of Political Economy, $81: 279-288$

Xin, X. (2011), A Study of Ties and Time-Varying Covariates in Cox Proportional Hazard Model, Yüksek Lisans Tezi, The Faculty of Graduate Studies of The University of Guelph.

Yardımcı E., Yardımcı O. ve Tümerdem Y. (1996), The Menopausalperiod and Health Problems, Journal of 19 May University Medical Faculty,13(1), 47-51. 